\title{
Downregulation of tumor suppressor gene ribonuclease T2 and gametogenetin binding protein 2 is associated with drug resistance in ovarian cancer
}

\author{
FUQIANG YIN ${ }^{1,2^{*}}$, LING LIU $^{1 *}$, XIA LIU ${ }^{3}$, GANG LI $^{1}$, LI ZHENG $^{1}$, \\ DANRONG LI ${ }^{1}$, QI WANG ${ }^{4}$, WEI ZHANG ${ }^{4}$ and $\mathrm{LI} \mathrm{LI}^{2,4}$ \\ ${ }^{1}$ Medical Scientific Research Centre, Guangxi Medical University, Nanning, Guangxi 530021; ${ }^{2}$ Key Laboratory \\ for High-Incidence Tumor Prevention and Treatment, Ministry of Education; ${ }^{3}$ Center for Translational \\ Medicine, Guangxi Medical University, Nanning; ${ }^{4}$ Department of Gynecologic Oncology, Affiliated \\ Tumor Hospital of Guangxi Medical University, Nanning, Guangxi 530021, P.R. China
}

Received March 24, 2014; Accepted April 30, 2014

DOI: $10.3892 /$ or.2014.3175

\begin{abstract}
Ribonuclease T2 (RNASET2) and gametogenetin binding protein $2(G G N B P 2)$ are tumor suppressor genes whose expression is downregulated in ovarian and other types of cancer. However, whether the proteins encoded by these genes are associated with drug resistance has rarely been studied. Using real-time quantitative polymerase chain reaction, in the present study we showed that RNASET2 and GGNBP2 mRNA levels were significantly lower in A2780-CBP (carboplatinresistant) and A2780-DDP (cisplatin-resistant) ovarian cancer cells than in the parental A2780 cells and were downregulated in drug-resistant ovarian cancer tissues compared with their drug-sensitive counterparts. These findings were consistent with the expression profiles determined from microarray data retrieved from the Gene Expression Omnibus Profiles database. Accordingly, we hypothesized that the downregulation of RNASET2 and GGNBP2 is involved in the development of drug resistance in ovarian cancer. A comprehensive bioinformatics analysis of the two genes was therefore conducted, including gene/protein-gene/protein interactions, biological process annotation, pathway enrichment of co-expressed genes and microRNA-mRNA analyses. The integrated results suggested that RNASET2 and GGNBP2 contributed to drug resistance in ovarian cancer, via direct or indirect interactions with a number of microRNAs, genes and proteins involved in a wide range of biological processes and pathways. The information provided in the present study provides insight for
\end{abstract}

Correspondence to: Professor Li Li, Department of Gynecologic Oncology, Affiliated Tumor Hospital of Guangxi Medical University, 71 Hedi Road, Nanning, Guangxi 530021, P.R. China

E-mail: lili@gxmu.edu.cn

*Contributed equally

Key words: ribonuclease $\mathrm{T} 2$, gametogenetin binding protein 2, ovarian cancer, drug resistance, bioinformatics further investigations of the drug resistance-related functions of RNASET2 and GGNBP2.

\section{Introduction}

Ovarian cancer is the most lethal gynecologic cancer, causing annually a large number of deaths throughout the world. Early stages of ovarian cancer are often asymptomatic such that the disease is usually diagnosed after it has disseminated beyond the ovaries (1). In fact, $70 \%$ of ovarian cancer patients present with advanced-stage disease (2). Although patients usually respond to initial therapy and cytoreductive surgery followed by adjuvant chemotherapy with platinum and paclitaxel (3), $\sim 70 \%$ of those with advanced-stage ovarian cancer experience recurrence. In many of these cases, the disease is incurable mainly due to the development of drug resistance (4).

Drug resistance can be intrinsic or acquired and arises from a variety of factors, including genetic differences in somatic cell tumors and individual patient-specific variations (5). In culture, cancer cells have been shown to become resistant to cytotoxic anticancer drugs through several different mechanisms, such as efflux pumps, cell cycle defects, apoptosis, DNA damage, metabolic alterations, changes in drug targets and compartmentalization (5). Some of the molecular mechanisms underlying the development of resistance have been characterized in cellular models of ovarian cancer. Johnson et al (6) described three general pathways; increased DNA damage tolerance/repair, decreased cell-drug associations and altered drug inactivation. All of these are thought to be involved in platinum-based resistance mechanisms in ovarian cancer. According to Sorrentino et al (7), drug resistance in ovarian cancer reflects the deregulation of growth factor receptor expression, defective DNA damage response, increased DNA repair activity and the increased activity of anti-apoptotic regulators. A more recent study suggested that targeting glycolytic, mitochondrial apoptotic and necrotic pathways offers promising therapeutic strategies in ovarian cancer (3). However, despite the large number of studies and increasing insight into the mechanisms of drug resistance in this disease, 
the 5-year survival rate of patients is only $\sim 40 \%$, and only modest improvement has been made over the past 40 years (2).

Tumor suppressor genes (TSGs) play regulatory roles in diverse cellular activities, including cell cycle checkpoint responses, mitogenic signaling, DNA damage repair, cell proliferation, differentiation, migration, protein ubiquitination and tumor angiogenesis $(8,9)$. TSGs have also been implicated in the drug resistance of ovarian cancer and their loss of function contributes to the development of cancer in general $(9,10)$. For example, expression of tumor suppressor PTEN is lower in drug-resistant than in drug-sensitive ovarian cancer cells. The overexpression of PTEN by transfection was shown to reverse chemoresistance to cisplatin, by inactivating the PI3K/AKT cell survival pathway (11). The TSGs BRCA1 and BRCA2 have been convincingly linked to ovarian cancer, and tumors with BRCA1/2 mutations frequently develop platinum resistance (12). In a literature review, Yin et al (10) identified 15 TSGs (such as BRCA1, PTEN and p53) that play critical roles in drug resistance and that, consequently, may serve as molecular targets for the treatment of chemoresistant ovarian cancer. Therefore, the targeting of drug resistance-related TSGs would provide the first steps in developing reasonable and feasible methods to meet the challenges posed by drug resistance in ovarian cancer.

TSGs may be of the class I or class II type. Class I TSGs lose function by deletion, rearrangement or mutation (13); class II TSGs are structurally intact in their sequence, yet are underexpressed or unexpressed due to downregulation or silencing in transcription or translation (14). Ribonuclease T2 (RNASET2) is a class II TSG associated with the suppression of ovarian cancer (15); it belongs to a group of genes encoding RNases and is highly conserved among species (16). RNases, including RNASET2, have many different functions, with a particularly important one being the regulation of cell growth (17). Consistent with these properties is the observation that in some human malignancies, such as lymphomas and glioma, RNASET2 expression is downregulated at the transcriptional level $(18,19)$. Monti et al (20) showed an apparent decrease in the antitumorigenic activity of RNASET 2 in melanoma cancer cells. In ovarian cancer, RNASET2 expression was shown to be significantly reduced in $30 \%$ of primary ovarian tumors and in $75 \%$ of ovarian tumor cell lines (15). Conversely, the transfection of RNASET2 into ovarian tumor cell lines suppressed their tumorigenicity in nude mice and induced marked cell senescence during in vitro growth (15). Besides its antitumorigenic activity, RNASET2 significantly reduces the metastatic potential of ovarian cancer (21), in addition to controlling ovarian tumorigenesis by modifying the cellular microenvironment and by inducing immunocompetent cells of the monocyte/macrophage lineage (22). Collectively, these studies indicate RNASET2 is a poorly explored member of the growing family of TSGs (22).

Gametogenetin binding protein 2 (GGNBP2), a potential TSG, is a highly conserved gene localized to the tumor-suppressor locus D17S800-D17S930 but also known to be involved in spermatogenesis (23). This gene is also known as ZNF403 and as laryngeal carcinoma related gene 1 (LCRG1), in the latter case since it was cloned from a laryngeal carcinoma (24). The expression of GGNBP2 is significantly reduced in $40 \%(12 / 30)$ of primary laryngeal carcinomas, where its primary tumor suppressive functions include control of the cell proliferation rate and of soft agar growth, tumor formation and tumor cell migration $(24,25)$. GGNBP2 knockdown alters the expression profiles of certain genes, such as upregulating p21 and downregulating MCM2. This participation in cell cycle regulatory pathways suggests that GGNBP2 contributes to the regulation of the G2/M transition of the cell cycle (25). In fact, cell cycle analysis demonstrated that the downregulation of GGNBP2 promotes $\mathrm{G} 2 / \mathrm{M}$ cell cycle arrest in a dose-dependent manner. Regarding the involvement of GGNBP2 in ovarian cancer, one study reported downregulation of the gene in six of ten different ovarian cancer cell lines (24).

Although RNASET2 and GGNBP2 are important TSGs and disturbances in their expression have been implicated in the development of ovarian and other types of cancer, the literature contains no reports of their specific association with drug resistance. A microarray analysis of carboplatin-sensitive and -resistant ovarian cancer cells carried out in our laboratory showed that the expression of RNASET2 and GGNBP2 is significantly decreased in resistant cells (26), indicating the involvement of these two genes in drug resistance. In the present study, on the basis of the results of real-time quantitative polymerase chain reaction (RT-qPCR) and comprehensive bioinformatics analysis, we were able to show, for the first time, that the downregulation of RNASET2 and GGNBP2 in drug-resistant ovarian cancer tissues/cells contributes to the regulation of drug resistance in ovarian cancer.

\section{Materials and methods}

Cell culture and tissue samples. The human epithelial ovarian cancer cell line A2780 was maintained in our laboratory and propagated in vitro by serial passage in RPMI-1640 supplemented with $10 \%$ fetal bovine serum. The A2780-CBP and A2780-DDP cell lines were developed by sequential exposure of A2780 cells to increasing concentrations of carboplatin and cisplatin, respectively. The resistance index of A2780-CBP and -DDP ovarian cancer cells was 2.0 and 1.8, respectively.

Ovarian cancer tissues were collected from patients surgically treated for primary epithelial ovarian cancer at the Department of Gynecologic Oncology, Affiliated Tumor Hospital of Guangxi Medical University. The tissue samples were evaluated by pathologists. All patients underwent conventional chemotherapy with 6-8 postoperative cycles of paclitaxel plus cisplatin (TP) or paclitaxel plus carboplatin (TC) after optimal cytoreductive surgery. They were followed up for a minimum of 1 year after the completion of chemotherapy. In addition, the patients were assigned to either the chemotherapy-resistant group $(n=10)$ or the chemotherapysensitive group $(n=10)$ in accordance with the 2013 guidelines National Comprehensive Cancer Network (NCCN). The median age of the patients was 50.8 years (range, 35-73 years). All of the malignant tissues were from stage II-III tumors, according to the International Federation of Gynecology and Obstetrics (FIGO) classification. The study was endorsed by the Ethics Committee of Guangxi Medical University. All patients received an explanation concerning the aims of the study and provided signed informed consent. Samples were collected from primary lesions during surgery and stored in a liquid nitrogen tank until they were used for mRNA isolation. 
RT-qPCR analysis. Total RNA from ovarian cancer cells/tissues was isolated using TRIzol reagent and digested with amplification-grade DNase I (both from Invitrogen, Carlsbad, CA, USA) prior to cDNA synthesis. The firststrand cDNA was synthesized using the Transcriptor First Strand cDNA Synthesis kit (Roche, Germany). RT-qPCR was performed with the FastStart Universal SYBR-Green Master kit (Roche). Data were collected with the StepOnePlus Real-Time PCR System (ABI, Foster City, CA, USA) in accordance with the manufacturer's instructions. The RT-qPCR gene-specific primers for RNASET2 were: (forward primer) 5'-ACCCTCCGGATTACTGGACA-3' and (reverse primer) 5'-TGCGATTGGGAAACGAGTGA-3'; for $G G N B P 2$, the forward primer was 5'-ATCACGCGAAGTCCTGAGTG-3' and the reverse primer was 5'-GGGAAAAGAGACGCTCCACA-3'. For $G A P D H$, used as the control, the forward primer was 5'-GAAGGTGAAGGTCGGAGT-3' and the reverse primer 5'-GAAGATGGTGATGGGATTT-3'.

Bioinformatics analysis. Microarray data on gene expression were retrieved from Gene Expression Omnibus (GEO) Profiles (http://www.ncbi.nlm.nih.gov/geoprofiles/). The gene/protein-gene/protein interaction network was generated with GeneMANIA (http://www.genemania.org/) (25); the annotation of biological processes was analyzed with the Coremine Medical online tool (http://www.coremine. com/medical/). The miRWalk online tool (http://www.umm. uni-heidelberg.de/apps/zmf/mirwalk/) was used for miRNA target-gene prediction (27). Data on genes co-expressed with RNASET2 and GGNBP2 according to the TCGA Ovarian 2 database were obtained from the Oncomine online database (https://www.oncomine.org/resource/login.html). The pathway enrichment was performed using the DAVID online tool (http://david.abcc.ncifcrf.gov/) $(28,29)$. The pathways in which the genes were involved were analyzed using the online database Kyoto Encyclopedia of Genes and Genomes (KEGG) (http://www.genome.jp/kegg/).

\section{Results}

RNASET2 and GGNBP2 mRNA expression is significantly downregulated in drug-resistant ovarian cancer cells/tissues. Based on the microarray data obtained in our laboratory (26) and the data retrieved from the GEO database (Fig. 1A), the expression of RNASET2 and GGNBP2 was significantly lower (at least 1.6-fold) in platinum- and vincristine-resistant ovarian cancer cells than in their drug-sensitive counterparts. This result was confirmed by measuring the expression of the two genes in all three ovarian cancer cell lines. Specifically, the RT-qPCR results showed large decreases in RNASET2 and GGNBP2 mRNA levels in A2780-CBP and -DDP cancer cells when compared with A2780 cells. Indeed, GGNBP2 expression was reduced by at least 5-fold in resistant cells (Fig. 1B). Further study of these genes in ovarian cancer tissues revealed that RNASET2 and GGNBP2 mRNA levels were significantly lower in drug-resistant than in drug-sensitive tissues (Fig. 1C and D). Compared with the average expression levels in ten sensitive cancers, those of RNASET2 and GGNBP2 in ten resistant cancers were decreased 3.2- and 7.4-fold, respectively. Collectively, the data on drug-resistant cells as provided in the GEO database, the results of our experiments in cultured drug-resistant-A2780 cells, and our analyses of drug resistance in ovarian cancer tissues consistently showed that the expression of RNASET2 and GGNBP2 mRNA is downregulated in ovarian cancer, indicating a role for these genes in the development of drug-resistant variants of these tumors.

Prediction and analysis of function based on gene/proteingene/protein interactions. The drug resistance-related functions of RNASET2 and GGNBP2 were analyzed using GeneMANIA (Fig. 2). RNASET2 was co-expressed, co-localized, physically interacted and shared protein domains and pathways directly/indirectly with a number of proteins. Specifically, direct genetic interactions were established between RNASET2 and checkpoint kinase 2 (CHEK2), programmed cell death 4 (PDCD4), phosphatase and tensin homolog (PTEN), split hand/foot malformation (ectrodactyly) type 1 (SHFM1) and Yes-associated protein 1 (YAP1). In addition, RNASET2 was found to be co-expressed directly with ring finger and WD repeat domain 2 (RFWD2). These results suggested that these genes/proteins and RNASET2 are functionally related.

CHEK2 is one of the critical kinases governing cell apoptosis, DNA damage repair and cell cycle checkpoint control in response to DNA damage signals. It is degraded at the protein level in response to cisplatin, through a ubiquitin-proteasome pathway. In ovarian cancer, the expression of CHEK2 is decreased in cisplatin-resistant ovarian cancer cell lines, suggesting a role for this kinase in chemoresistance (30).

PDCD4 is another TSG and its expression was shown to enhance chemosensitivity in renal and prostate cancer cell lines $(31,32)$. In ovarian cancer, PDCD4 promotes cisplatin-induced apoptosis, mainly by activating the death receptor pathway and PDCD4 gene transfer in combination with cisplatin therapy may break the chemotherapeutic resistance of ovarian cancer cells (33).

PTEN is a well-known TSG associated with cancer development through the ERK1/2 signaling (34) and PI3K/Akt/mTOR $(35,36)$ pathways. It interacts with TSGs (such as p53 and BRCA1) that contribute to the development of drug resistance in several types of cancer (37). In ovarian cancer, PTEN contributes to multidrug resistance through cell cycle regulation, apoptosis and the PI3K/Akt pathway $(38,39)$.

Yuan et al (40) demonstrated that YAP1 is a TSG. Knockdown of the gene in breast cell lines resulted in several abnormal cell behaviors, including inhibition of the response of these cells to taxol. Accordingly, the authors concluded that YAP1 plays a role in drug resistance.

SHFM1 is a TSG required for the stability of BRCA2 (41), yet it has also been implicated in acquired drug resistance in ovarian cancer (42).

Finally, RFWD2, also known as constitutive photomorphogenic 1 (COP1), is a newly discovered TSG $(43,44)$. As reported by Migliorini et al (44), it exerts its tumor suppressor function in part by antagonizing c-Jun oncogenic activity. A recent study suggested RFWD2 as a target for gene therapy in the treatment of gastric cancer, suggesting the involvement of this protein in drug resistance in cancer (45).

GGNBP2 is associated with fewer genes/proteins than RNASET2. As shown in Fig. 2, GGNBP2 is co-expressed only 

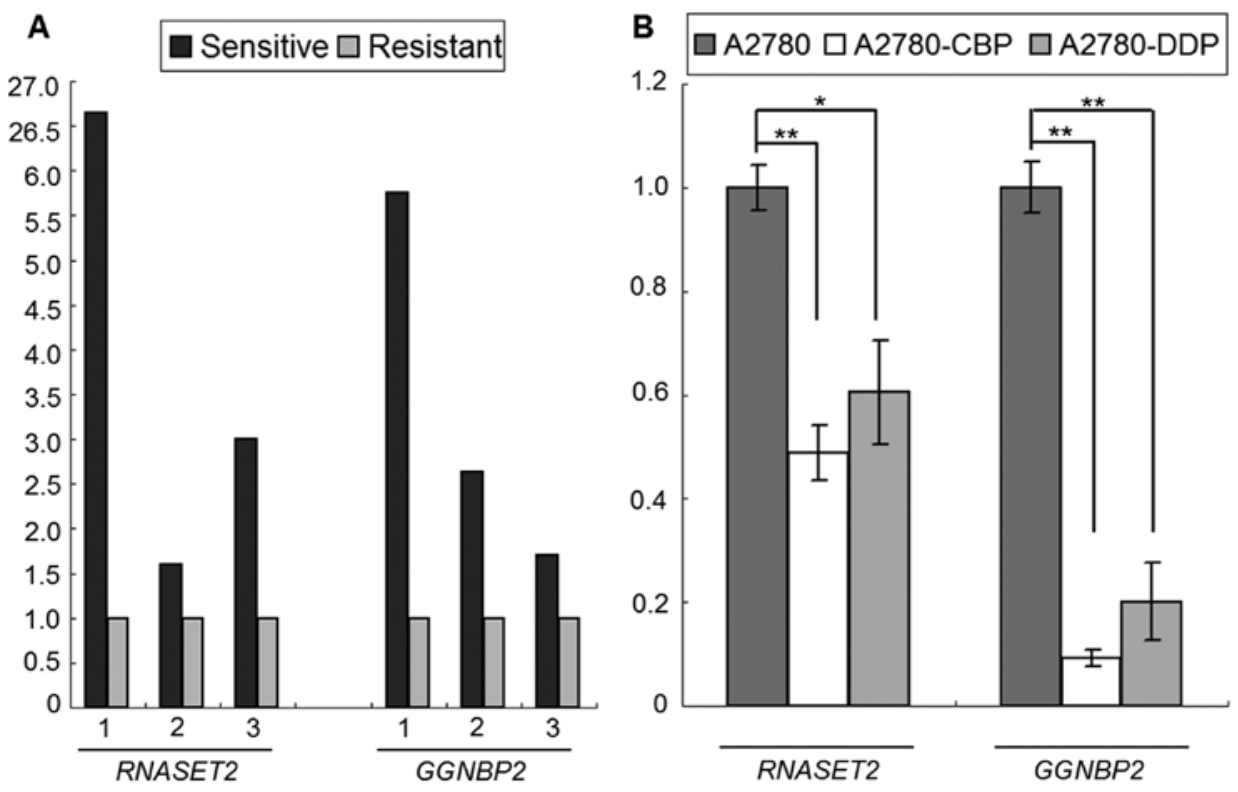

\section{C}
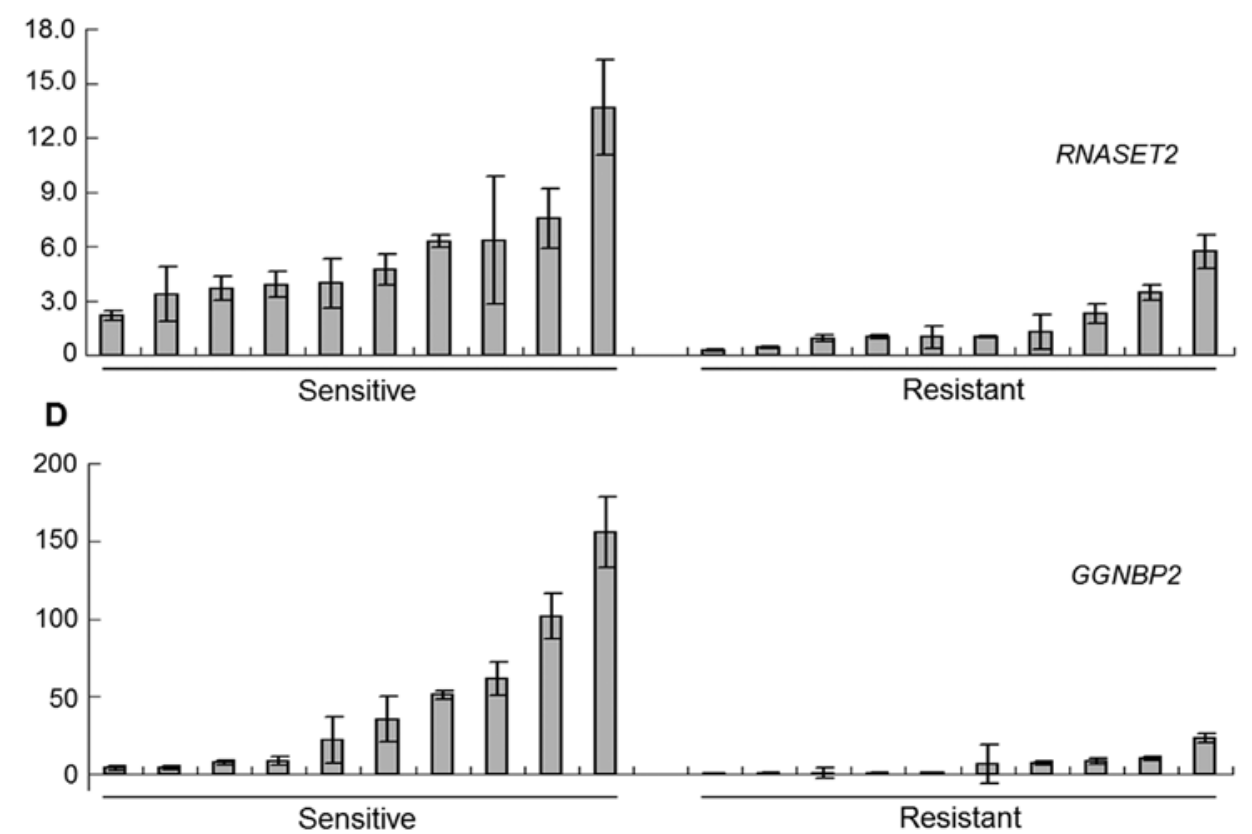

Figure 1. RNASET2 and GGNBP2 expression at the transcriptional level is downregulated in drug-resistant ovarian cancer cells/tissues. (A) RNASET2 and GGNBP2 mRNA expression in drug-resistant ovarian cancer cells, as determined by microarray analysis. Lane 1, carboplatin-sensitive and -resistant SKOV3 ovarian cancer cells (4 biological replicates each) from our laboratory; Lane 2, vincristine-sensitive and -resistant SKOV3 ovarian cancer cells (4 biological replicates each) according to the GEO profiles database (GDS2963); Lane 3, platinum-sensitive and -resistant A2780 ovarian cancer cells (10 biological replicates each) according to the GEO profiles database (GDS3754). Gene expression in the drug-resistant cancer cells was normalized to 1.0. (B) RNASET2 and GGNBP2 mRNA expression in A2780, A2780-CBP and -DDP ovarian cancer cells. " $\mathrm{p}<0.05,{ }^{* *} \mathrm{p}<0.01$. (C) RNASET2 mRNA expression in drug-sensitive and -resistant ovarian cancers. (D) GGNBP2 mRNA expression in drug-sensitive and -resistant ovarian cancers. RNASET2, ribonuclease T2; GGNBP2, gametogenetin binding protein 2 .

with zinc finger CCCH-type containing 11A (ZC3H11A) and genetically interacts with WW domain containing oxidoreductase (WWOX). ZC3H11A is a poorly characterized protein that belongs to a large family of zinc finger proteins, with 58 known members (46). Zinc finger proteins are known to mediate the epithelial-mesenchymal transition, which in lung cancer is related to drug resistance (47). Thus, the function of $\mathrm{ZC} 3 \mathrm{H} 11 \mathrm{~A}$, as a member of the zinc finger protein family, may also be drug resistance-related. As a TSG, WWOX plays important roles in ovarian and many other types of cancers (48). For example, the overexpression of WWOX preferentially inhibits the viability of human glioblastoma cells expressing mutant p53 and induces apoptosis via a mechanism independent of the intrinsic apoptotic pathway (49). Conversely, WWOX suppression by RNA interference reverses platinum resistance in DDP-resistant SKOV3 ovarian cancer cells (50).

In the present study, we determined direct interactions of six genes/proteins with RNASET2 and two with GGNBP2, and in all cases these were linked to drug resistance in ovarian and other types of cancers. In addition, indirect interactions 


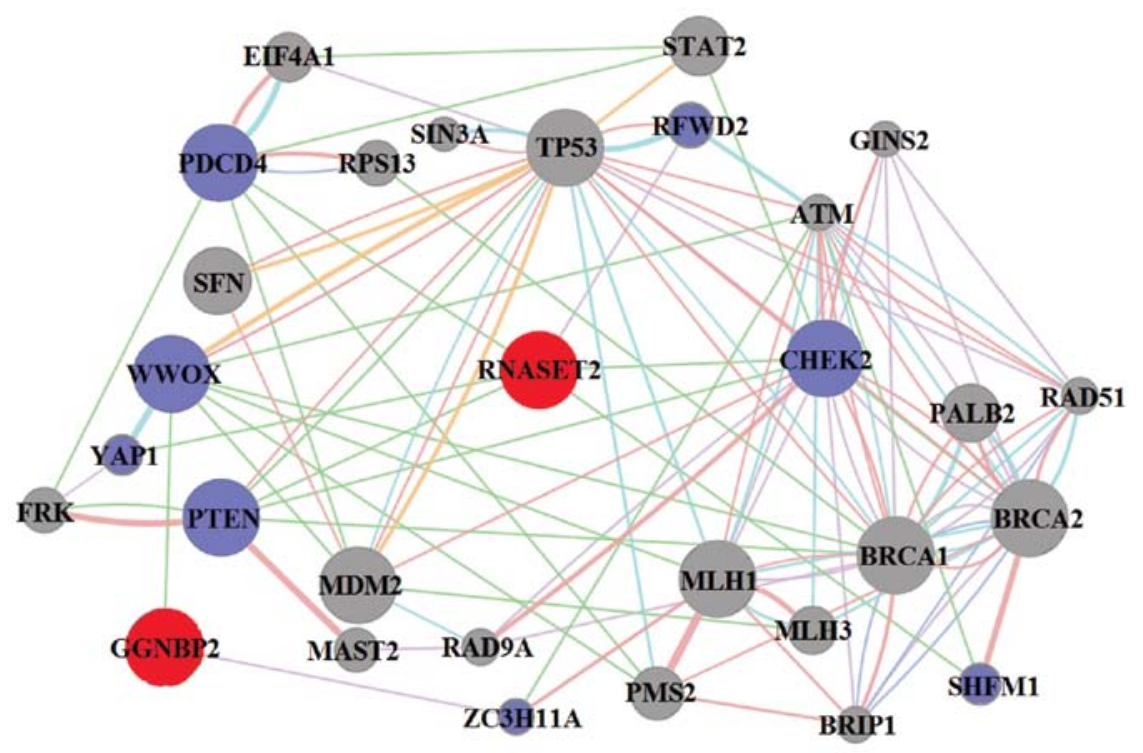

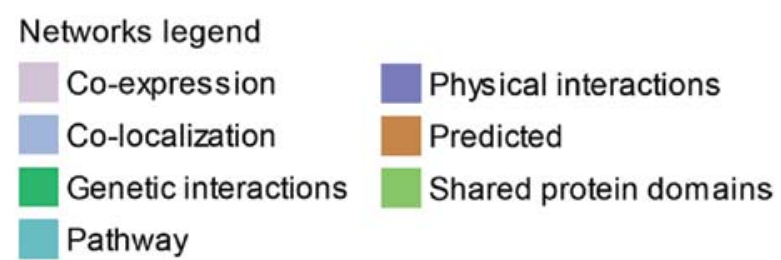

Figure 2. Gene/protein interaction networks of RNASET2 and GGNBP2, generated using the GeneMANIA online tool. Queries in red refer to target genes/proteins; those in blue refer to the genes/proteins that interact directly with the target. RNASET2, ribonuclease T2; GGNBP2, gametogenetin binding protein 2.

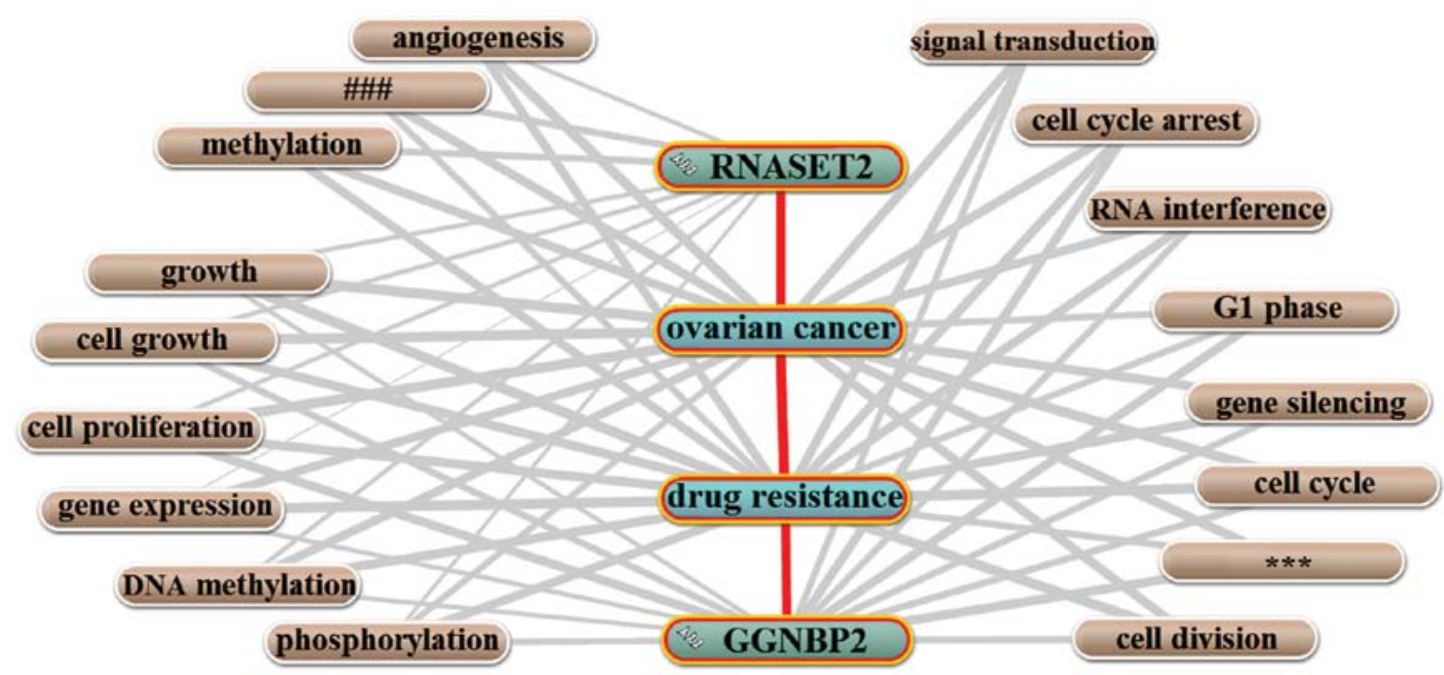

Figure 3. Annotated biological processes involving RNASET2 and GGNBP2 and their relationships with both drug resistance and ovarian cancer, as deter-

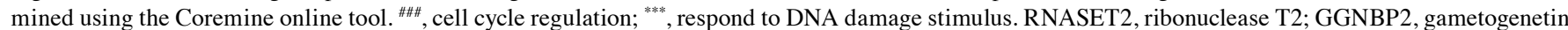
binding protein 2 .

between several TSGs, such as TP53, MLH1, MLH3, BRCA1, and BRCA2, and RNASET2, and GGNBP2 were demonstrated. All of these TSGs are linked to drug resistance in ovarian cancer (10), a relationship that supports our conclusion that RNASET2 and GGNBP2 are associated with drug resistance in ovarian cancer.

Functional prediction based on the annotated biological process. In Coremine Medical (51), gene and protein names are cross-referenced to terms relevant to an understanding of their biological function and importance in disease. We therefore used the Coremine online tool and probabilistic scoring $(\mathrm{p}<0.009)$ to annotate RNASET2 and GGNBP2 with respect to biological processes. As shown in Fig. 3, 17 biological processes closely associated with ovarian cancer, drug resistance, and the two genes were annotated, suggesting their mutual involvement in drug resistance in ovarian cancer. Among the nine processes annotated to RNASET2, three were related to 
Table I. The 8 miRNAs most strongly targeting GGNBP2 and RNASET2, and their functions in cancer.

miRNA-gene interaction prediction tools

\begin{tabular}{|c|c|c|c|c|c|c|c|c|c|c|c|}
\hline \multirow[b]{2}{*}{ Gene name } & \multirow[b]{2}{*}{ MicroRNA } & & \multirow{2}{*}{$\begin{array}{l}\text { Drug resistance and related } \\
\text { functions in cancer (ref.) }\end{array}$} \\
\hline & & A & B & $\mathrm{C}$ & $\mathrm{D}$ & $\mathrm{E}$ & $\mathrm{F}$ & G & $\mathrm{H}$ & I & \\
\hline \multirow[t]{8}{*}{$G G N B P 2$} & hsa-miR-135a & 1 & 1 & 1 & 1 & 1 & 1 & 1 & 1 & 1 & Drug resistance in breast cancer (52) \\
\hline & hsa-miR-23b & 1 & 1 & 1 & 1 & 1 & 1 & 1 & 1 & 1 & $\begin{array}{l}\text { Drug resistance in ovarian cancer (53) } \\
\text { and breast cancer (52) }\end{array}$ \\
\hline & hsa-miR-135b & 1 & 1 & 1 & 1 & 1 & 0 & 1 & 1 & 1 & Drug resistance in esophageal cancer (54) \\
\hline & hsa-miR-23a & 1 & 1 & 1 & 1 & 1 & 0 & 1 & 0 & 1 & Drug resistance in ovarian cancer (55) \\
\hline & hsa-miR-150 & 1 & 1 & 0 & 1 & 1 & 0 & 1 & 1 & 1 & Drug resistance in breast cancer (52) \\
\hline & hsa-miR-323-3p & 1 & 1 & 1 & 1 & 1 & 0 & 1 & 0 & 1 & - \\
\hline & hsa-miR-210 & 1 & 1 & 1 & 1 & 0 & 0 & 1 & 0 & 1 & Drug resistance in breast cancer (56) \\
\hline & hsa-miR-224 & 1 & 1 & 1 & 1 & 0 & 0 & 1 & 0 & 1 & $\begin{array}{l}\text { Drug resistance in lung cancer cells (57) } \\
\text { and gastric cancer cells (58) }\end{array}$ \\
\hline \multirow[t]{8}{*}{ RNASET2 } & hsa-miR-758 & 0 & 1 & 0 & 1 & 0 & 0 & 1 & 0 & 1 & Drug resistance in breast cancer (52) \\
\hline & hsa-miR-320c & 0 & 1 & 0 & 1 & 0 & 0 & 1 & 0 & 1 & - \\
\hline & hsa-miR-320a & 0 & 1 & 0 & 1 & 0 & 0 & 1 & 0 & 1 & $\begin{array}{l}\text { Cell proliferation in colon cancer cell (59) } \\
\text { and tumor invasion in colorectal cancer (60) }\end{array}$ \\
\hline & hsa-miR-320d & 0 & 1 & 0 & 1 & 0 & 0 & 1 & 0 & 1 & $\begin{array}{l}\text { Regulation of stem cell differentiation in } \\
\text { colon cancer stem cells ( } 61)\end{array}$ \\
\hline & hsa-miR-320b & 0 & 1 & 0 & 1 & 0 & 0 & 1 & 0 & 1 & - \\
\hline & hsa-miR-635 & 0 & 1 & 0 & 1 & 0 & 0 & 0 & 0 & 1 & - \\
\hline & hsa-miR-22 & 0 & 1 & 0 & 1 & 0 & 0 & 1 & 0 & 0 & Drug resistance in ovarian cancer (62) \\
\hline & hsa-miR-1257 & 0 & 1 & 0 & 0 & 0 & 0 & 1 & 0 & 1 & $\begin{array}{l}\text { Tumor dedifferentiation and/or progression } \\
\text { in liposarcoma (63) }\end{array}$ \\
\hline
\end{tabular}

A, DIANAmT; B, miRanda; C, miRDB; D, miRWalk; E, RNAhybrid; F, PICTAR4; G, PICTAR5; H, RNA22; I, Targetscan; 1, predicted by the software; 0, not predicted; GGNBP2, gametogenetin binding protein 2; RNASET2, ribonuclease T2.

growth, cell growth and cell proliferation, consistent with the theory that the drug resistance-related functions of RNASET2 mainly proceed through the regulation of cell growth and the RNase activity of RNASET2 (17). GGNBP2 annotated with 14 of the 17 processes: three (growth, cell growth and cell proliferation) were cell-growth related, four (gene expression, DNA methylation, RNA interference and gene silencing) were gene-expression related, and three (cell cycle arrest, G1 phase and cell cycle) were cell cycle related. Of these, the relationship between the cell cycle-related function of GGNBP2 and drug resistance is in agreement with a previous study in which GGNBP2 was shown to be involved in cell cycle regulation during cancer development (25).

Functional prediction based on the functionality of the miRNAs that target them. Among the transcriptional targets of GGNBP2 and RNASET2 were 228 and 179 miRNAs, respectively, as predicted through miRWalk, which is made up of ten miRNA-mRNA prediction tools. Eight miRNAs, i.e., those yielding the highest score for each gene, were selected for subsequent analysis (Table I). As shown in Table I, except for hsa-miR-323-3p, all the miRNAs that targeted GGNBP2 influenced drug resistance in ovarian and other types of cancers. For RANSET2, although only hsa-miR-758 and hsa-miR-22 were specifically involved in drug resistance in ovarian and breast cancer, three other miRNAs (hsa-miR-320a, hsa-miR-320d and hsa-miR-1257) contributed to drug resistance-related processes, such as cell proliferation, tumor invasion and cell differentiation. Collectively, among eight miRNAs most strongly targeting RNASET2 and especially GGNBP2, the majority were involved in drug resistance in ovarian and other cancers, suggesting that the two genes also mediate drug resistance.

Potential pathways by which RNASET2 and GGNBP2 contribute to drug resistance. Pathway enrichment of the genes co-expressed with RNASET2 and GGNBP2 in drugresistant ovarian cancer cells was performed to mine the possible pathways in which these two TSGs may exercise their drug resistance-related functions in ovarian cancer. Genes co-expressed with RNASET2 and GGNBP2 in eight irinotecan-resistant, four paclitaxel-resistant and five topotecan-resistant ovarian cancer cells were retrieved from the Oncomine online database. Of the co-expressed genes, the 50 genes with the highest correlation efficiency with GGNB2 and RNASET2 were selected for further analysis (Table II). For GGNBP2, two pathways (cytokine-cytokine receptor interaction and chemokine signaling pathway) were found to be enriched, as determined using DAVID $(28,29)$, whereas with RNASET2 no enriched pathway was identified. Thus, a basic search in the KEGG database was performed to retrieve the pathways to which the co-expressed genes belonged. This 
Table II. The 50 genes most strongly co-expressed with RNASET2 and GGNBP2 in drug-resistant ovarian cancer cells and their drug resistance-associated pathways.

Genes co-expressed in drug-resistant ovarian cancer cells ${ }^{\mathrm{a}}$ (correlation efficiency $>0.873$ )
Genes belong to certain pathway based on the KEGG

Annotated database $^{c}$ and the pathways were involved in the pathway $^{\mathrm{b}}$ drug resistance in ovarian and other cancers (ref.)

\section{RNASET2}

$$
\begin{aligned}
& \text { FGFR1OP, CCR6, T, PRR18, SFT2D1, BRP44L, } \\
& \text { RPS6KA2, C6orF118, PDE10A, UNC93A, TTLL2, TCP10, } \\
& \text { GPR31, TCP10L2, QKI, PACRG, PARK2, SMOC2, } \\
& \text { DACT2, PSMB1, TBP, PDCD2, FAM120B, DLL1, THBS2, } \\
& \text { PHF10, WDR27, C6orf120, TCTE3, C6orf70, HGC6.3, } \\
& \text { KIF25, FRMD1, C6orf124, MLLT4, MAP3K4, AGPAT4, } \\
& \text { SOD2, WTAP, TCP1, ACAT2, PNLDC1, MRPL18, MAS1, } \\
& \text { IGF2R, LPA, LPAL2, SLC22A3, SLC22A2, SLC22A1 } \\
& \text { GGNBP2 } \\
& \text { DHRS11, MYO19, PIGW, MRM1, ZNHIT3, AATF, LHX1, } \\
& \text { SLFN13, SLFN11, SLFN12, CCL3, CCL23,CCL18, } \\
& \text { MMP28, TAF15, C17orf50,CCL5, C17orf66, GAS2L2, } \\
& \text { RASL108, LYZL6, RDM1,CCL16, CCL14, AP2B1, } \\
& \text { SLFN12L, PEX12, SLFN14, SLFN5, AMAC1,C17orf75, } \\
& \text { ZNF207, RHBDL3, PSMD11,CDK5R1, MYO1D, } \\
& \text { TMEM98, LRRC37B, RHOT1, UTP6, C17orf79, SUZ12, } \\
& \text { C17orf102, TMEM132E, CCL7, CCL1, CCL13,CCL8, } \\
& \text { CCL11, CCL2 }
\end{aligned}
$$

\section{GGNBP2}

\author{
CCR6, I (69) and II (71) \\ PARK2, III (77) \\ THBS2, IV (77) and V $(39,78)$ \\ $T C P 1, \mathrm{~V}(39,78)$ \\ $P S M B 1, \mathrm{VI}(30,79)$ \\ MAP3K4, VII (80-83)
}

\author{
I $\quad P I G W$, VIII (3) \\ II $\quad C C L 3, C C L 5, C C L 7, C C L 1, C C L 8$ and $C C L 11, \mathrm{I}(69)$, \\ II (71) \\ CCL23, CL18, CCL16 and CCL14, I (69) \\ $C C L 2$, I (69) and IX $(73,74)$ \\ CCL13, IX $(73,74)$ \\ $A P 2 B 1, \mathrm{X}(84)$
}

${ }^{\mathrm{a}}$ Genes co-expressed with RNASET2 and GGNBP2 in 8 irinotecan-resistant, 4 paclitaxel-resistant and 5 topotecan-resistant ovarian cancer cells in accordance with Oncomine online tool and database. ${ }^{b}$ Pathway enrichment of the genes was determined using DAVID. ${ }^{\circ}$ Pathways of the genes co-expressed with RNASET2 and GGNBP2 were searched in the KEGG online database. I, Cytokine-cytokine receptor interaction; II, chemokine signaling pathway; III, ubiquitin-mediated proteolysis; IV, focal adhesion; V, PI3K-Akt signaling pathway; VI, proteasome pathway; VII, mitogen-activated protein kinase signaling pathway; VIII, metabolic pathways; IX, NF- $\mathrm{BB}$ signaling pathway; X, endocytosis pathway; XI, Epstein-Barr virus infection. RNASET2, ribonuclease T2; GGNBP2, ametogenetin binding protein 2; KEGG, Kyoto Encyclopedia of Genes and Genomes.

resulted in the identification of 12 RNASET2-associated genes and 19 GGNBP2-associated genes as a member of certain pathways, several of which could be related to drug resistance in ovarian and other types of cancers (Table II).

For example, the genes THBS2 and TCP1, co-expressed with RNASET2, are part of the PI3K/Akt signaling pathway, which suggested that it is among the pathways used by this TSG to regulate drug resistance. In fact, a strong association between PI3K/Akt signaling and drug resistance has been shown in ovarian cancer $(11,39)$. Pathway enrichment analysis suggested that the hypomethylation-mediated activation of cell growth-promoting pathways, including PI3K/Akt, contributes to the onset of chemoresistance in ovarian cancer cells (64). Studies on the genes involved in the activation of this pathway identified two mechanisms, PTEN reduction and PIK3CA mRNA amplification, that finally contribute to cisplatin resistance in an ovarian cancer cell line (39). Similarly, the chemoresistance caused by interleukin (IL)- 6 and -8 expression is associated with the activation of several pathways, including PI3K/Akt $(65,66)$. Accordingly, altered RNASET2 expression in drug-resistant ovarian cancers may well contribute to chemoresistance by activating the PI3K/Akt signaling pathway.

The cytokine-cytokine receptor interaction and chemokine signaling pathways were enriched in the 50 genes most highly co-expressed with GGNBP2 in drug-resistant ovarian cancer cells, suggesting that GGNBP2 contributes to drug resistance via these two pathways. In tumorous spleens, downregulated genes that have been linked to transformation are mainly associated with the cytokine-cytokine receptor interaction pathway (67); similarly, most of the genes associated with lung carcinogenesis are annotated to this same pathway (68). Cytokine-cytokine receptor interactions with drug resistance are thought to proceed via tumor-stroma communication, as shown in primary tumors with a high risk of relapse (69). In a non-small cell lung cancer cell line, functional annotation showed that genes with altered expression induced by docetaxel are strongly co-related with several pathways, including cytokine-cytokine receptor interactions (70). These results provide evidence of the interaction between the cytokine-cytokine receptor pathway and the drug resistance of several types of tumor. 


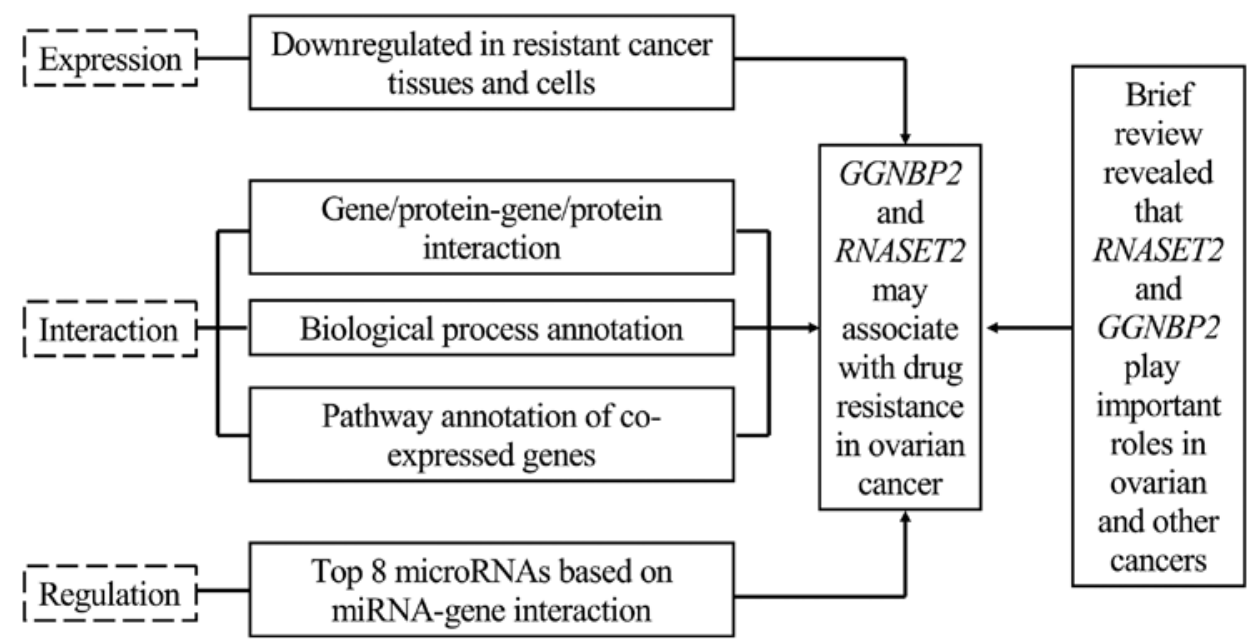

Figure 4. Summary of the bioinformatics analysis of the association of GGNBP2 and RNASET2 with drug resistance in ovarian cancer. RNASET2, ribonuclease T2; GGNBP2, gametogenetin binding protein 2 .

Crosstalk networks among pathways associated with prostate cancer (primary and metastatic), by integrating protein-protein interactions and KEGG pathways, point to the regulation of multiple processes, including drug resistance, by the chemokine signaling pathway during cancer progression (71). Oxaliplatin-induced chemokine signaling was shown to reinforce NF- $\mathrm{KB}$ transcriptional activity, thus potentiating the resistance of prostate cancer cells to this platinum-based drug (72). The NF- $\kappa B$ signaling pathway contains two genes (CCL2 and CCL13) that are co-expressed with GGNBP2 in drug-resistant ovarian cancer cells. Many studies have shown that this pathway plays a critical role in anti-apoptosis and the drug resistance of tumor cells during chemotherapy (73). For example, curcumin downregulates the multidrug-resistance $m d r l b$ gene by inhibiting the PI3K/Akt and NF- $\mathrm{KB}$ signaling pathways in multidrug-resistant L1210/Adr cells (74). Pre-clinical models demonstrated that many chemotherapy drugs, such as platinum-based agents, anthracyclines and taxanes, promote NF- $\kappa \mathrm{B}$ pathway activation, which finally leads to chemoresistance through the subsequent activation of a multitude of mediators including anti-apoptotic genes (75). In ovarian cancer, NF- $\mathrm{\kappa B}$ functions as an oncogene in drug-resistant ovarian cancer cells and exerts its anti-apoptotic effects by repressing mitogen-activated protein kinase phosphorylation in aggressive chemoresistant cell lines (76).

Thus, some of the genes co-expressed with RNASET2 and GGNBP2 in drug-resistant ovarian cancer cells belong to pathways associated with drug resistance, suggesting the similar involvement of these two TSGs. In particular, GGNBP2 may participate in the regulation of drug resistance in ovarian cancer via cytokine-cytokine receptor interactions, chemokine signaling and NF- $\mathrm{KB}$ signaling, whereas for RNASET2, the $\mathrm{PI} 3 \mathrm{~K} / \mathrm{Akt}$ pathway is relevant.

\section{Discussion}

Drug resistance is an important obstacle to successful chemotherapeutic treatment in ovarian cancer and causes treatment failure in over $90 \%$ of patients with metastatic disease (86). Several mechanisms, including DNA damage repair and disrup- tions in the cell cycle, apoptosis and metabolism, are associated with the rise of drug resistance in ovarian cancer (3,7), mostly through aberrant gene expression. As key regulators of genes related to drug resistance, the mining and exploration of TSGs can provide insights into meeting the therapeutic challenge of drug resistance in ovarian cancer. The prediction of gene function based on comprehensive bioinformatics analysis offers a valuable tool for gene function mining. For example, on the basis of a comprehensive bioinformatics analysis, Yin et al (87) reported the association of SPARCL1 and CCL21 with drug resistance in ovarian cancer. In another study, 15 TSGs associated with drug resistance in ovarian cancer were analyzed by comprehensive bioinformatics to better understand the relationships of these genes to drug resistance (10).

The Gene Expression Omnibus (GEO), a public repository at the National Center for Biotechnology Information (NCBI), stores tens of millions of expression profiles, including those obtained from microarray-based experiments measuring mRNA abundance (88). The identification of large-scale networks of molecular interactions within the cell has highlighted the need to go beyond one-dimensional approaches to study gene/protein function (89). One such alternative is GeneMANIA, a fast and highly accurate web-based database and tool for the prediction of gene function on the basis of multiple networks, as determined from varied genomic or proteomic data/sources (90). Coremine Medical is a product of the PubGene Company, which itself grew out of the PubGene online tool, a gene/protein database and web-based tool for literature mining. By the automated analysis of titles and abstracts in over 10 million MEDLINE records, Coremine Medical creates a gene-to-gene co-citation network for millions of named human genes. The identified relationship networks provide both an overview of related terms and an intuitive system for exploring the information space (91). In the present study, the GEO database was used to retrieve data on RNASET2 and GGNBP2 expression in drug-sensitive and drug-resistant ovarian cancer cells; GeneMANIA and Coremine Medical were then used to predict the functions of RNASET2 and GGNBP2 through both their interaction networks and annotated biological processes. 
MicroRNAs (miRNAs) are a class of small (22 bp) endogenous non-coding RNAs that regulate gene expression and thus many cellular processes, both pathological and physiological, by binding to the 3'-UTR of the target mRNA, causing mRNA cleavage, destabilization or translational repression (92-95). This method of post-transcriptional gene regulation has been shown to play a crucial role in drug resistance in many types of cancers, including ovarian cancer (7). However, the specificity of miRNAs for their target genes also makes them of great interest in diagnostics, prognosis and therapy (96) and in predicting gene function. miRWalk is a comprehensive database on miRNA-mRNA interactions that gathers predicted and validated miRNA binding sites on all mRNAs, mitochondrial genes, and the 10-kb upstream flanking regions of all known genes in humans, mice and rats. More importantly, it is a real-time database in which the 'Validated Target' module is updated every month and the 'Predicted Target' module every 6 months (27). As a result, the functional prediction of genes as determined by their miRNAs through miRWalk is both feasible and reliable.

In the present study, RNASET2 and GGNBP2 were shown to be notably and consistently downregulated in drug-resistant ovarian cancers and ovarian cancer cells, which suggested the involvement of these TSGs in drug resistance. Support for this hypothesis came from a network analysis based on gene/protein-gene/protein interaction networks and biological processes annotation. The former indicated that RNASET 2 and GGNBP2 directly interact with many genes/proteins (Fig. 2), all of which are associated with drug resistance in ovarian cancer. Similarly, the annotated biological processes analysis related RNASET2 and GGNBP2 mainly to processes closely linked to drug resistance (Fig. 3). In addition, determinations of miRNA-mRNA interaction showed that among the eight miRNAs most strongly targeting RNASET2 and GGNBP2 (Table I), the majority were involved in the regulation of drug resistance in ovarian and other cancers, suggesting roles for the two target genes in drug resistance. Further support of an association between RNASET2 and GGNBP2 and drug resistance came from a bioinformatics analysis of the drug resistance-related pathways in which their co-expressed genes were involved (Table II).

Currently, there are no data on the genetic pathways related to RNASET2 and GGNBP2, either in the literature or in the KEGG database. Instead, in the present study, examination of the pathways enriched in the expression of genes co-expressed with RNASET2 and GGNBP2 in drug-resistant ovarian cancer cells suggested that the downregulation of the former resulted in drug resistance through the activation of the PI3K-Akt signaling pathway, whereas for the latter, cytokine-cytokine receptor interactions, chemokine signaling pathways and NF- $\mathrm{kB}$ signaling were implicated.

Collectively, on the basis of our studies of gene expression at the transcriptional level, protein interactions, annotated biological processes, miRNA-gene interactions and pathway analysis (Fig. 4), we were able to attribute the downregulation of RNASET2 and GGNBP2 in drug-resistant ovarian cancers and ovarian tumor cells to drug resistance in ovarian cancer. The present study sets the stage for further experimental investigations into the associations between RNASET2 and GGNBP2 and drug resistance.

\section{Acknowledgements}

This study was supported by the National Natural Science Foundation of China (grant no. 81302283), and the Youth Science Foundation of Guangxi Medical University (no. GXMUYSF201205).

\section{References}

1. Balch C, Huang TH, Brown R and Nephew KP: The epigenetics of ovarian cancer drug resistance and resensitization. Am J Obstet Gynecol 191: 1552-1572, 2004.

2. Siegel R, Naishadham D and Jemal A: Cancer statistics, 2012. CA Cancer J Clin 62: 10-29, 2012.

3. Suh DH, Kim MK, No JH, Chung HH and Song YS: Metabolic approaches to overcoming chemoresistance in ovarian cancer. Ann N Y Acad Sci 1229: 53-60, 2011.

4. Matsuo K, Eno ML, Im DD, Rosenshein NB and Sood AK: Clinical relevance of extent of extreme drug resistance in epithelial ovarian carcinoma. Gynecol Oncol 116: 61-65, 2010.

5. Gottesman MM: Mechanisms of cancer drug resistance. Annu Rev Med 53: 615-627, 2002.

6. Johnson SW, Ozols RF and Hamilton TC: Mechanisms of drug resistance in ovarian cancer. Cancer 71: 644-649, 1993.

7. Sorrentino A, Liu CG, Addario A, Peschle C, Scambia G and Ferlini C: Role of microRNAs in drug-resistant ovarian cancer cells. Gynecol Oncol 111: 478-486, 2008.

8. Sager R: Tumor suppressor genes: the puzzle and the promise. Science 246: 1406-1412, 1989.

9. Sherr CJ: Principles of tumor suppression. Cell 116: 235-246, 2004.

10. Yin F, Liu X, Li D, Wang Q, Zhang W and Li L: Tumor suppressor genes associated with drug resistance in ovarian cancer (Review). Oncol Rep 30: 3-10, 2013.

11. Wu H, Cao Y, Weng D, Xing H, Song X, Zhou J, Xu G, Lu Y, Wang S and Ma D: Effect of tumor suppressor gene PTEN on the resistance to cisplatin in human ovarian cancer cell lines and related mechanisms. Cancer Lett 271: 260-271, 2008.

12. Swisher EM, Sakai W, Karlan BY, Wurz K, Urban N and Taniguchi T: Secondary BRCAl mutations in BRCAl-mutated ovarian carcinomas with platinum resistance. Cancer Res 68: 2581-2586, 2008.

13. Haber D and Harlow E: Tumour-suppressor genes: evolving definitions in the genomic age. Nat Genet 16: 320-322, 1997.

14. Jones PA and Laird PW: Cancer epigenetics comes of age. Nat Genet 21: 163-167, 1999.

15. Acquati F, Morelli C, Cinquetti R, Bianchi MG, Porrini D, Varesco L, Gismondi V, Rocchetti R, Talevi S, Possati L, Magnanini C, Tibiletti MG, Bernasconi B, Daidone MG, Shridhar V, Smith DI, Negrini M, Barbanti-Brodano G and Taramelli R: Cloning and characterization of a senescence inducing and class II tumor suppressor gene in ovarian carcinoma at chromosome region 6q27. Oncogene 20: 980-988, 2001.

16. Trubia M, Sessa L and Taramelli R: Mammalian Rh/T2/Sglycoprotein ribonuclease family genes: cloning of a human member located in a region of chromosome $6(6 \mathrm{q} 27)$ frequently deleted in human malignancies. Genomics 42: 342-344, 1997.

17. McClure BA, Haring V, Ebert PR, Anderson MA, Simpson RJ, Sakiyama F and Clarke AE: Style self-incompatibility gene products of Nicotlana alata are ribonucleases. Nature 342: 955-957, 1989.

18. Steinemann D, Gesk S, Zhang Y, Harder L, Pilarsky C, Hinzmann B, Martin-Subero JI, Calasanz MJ, Mungall A, Rosenthal A, Siebert R and Schlegelberger B: Identification of candidate tumor-suppressor genes in $6 \mathrm{q} 27$ by combined deletion mapping and electronic expression profiling in lymphoid neoplasms. Genes Chromosomes Cancer 37: 421-426, 2003.

19. Kim TY, Zhong S, Fields CR, Kim JH and Robertson KD: Epigenomic profiling reveals novel and frequent targets of aberrant DNA methylation-mediated silencing in malignant glioma. Cancer Res 66: 7490-7501, 2006.

20. Monti L, Rodolfo M, Lo Russo G, Noonan D, Acquati F and Taramelli R: RNASET2 as a tumor antagonizing gene in a melanoma cancer model. Oncol Res 17: 69-74, 2008. 
21. Acquati F, Possati L, Ferrante L, Campomenosi P, Talevi S, Bardelli S, Margiotta C, Russo A, Bortoletto E, Rocchetti R, Calza R, Cinquetti R, Monti L, Salis S, Barbanti-Brodano G and Taramelli R: Tumor and metastasis suppression by the human RNASET2 gene. Int J Oncol 26: 1159-1168, 2005.

22. Acquati F, Bertilaccio S, Grimaldi A, Monti L, Cinquetti R, Bonetti P, Lualdi M, Vidalino L, Fabbri M, Sacco MG van Rooijen N, Campomenosi P, Vigetti D, Passi A, Riva C, Capella C, Sanvito F, Doglioni C, Gribaldo L, Macchi P, Sica A, Noonan DM, Ghia P and Taramelli R: Microenvironmental control of malignancy exerted by RNASET2, a widely conserved extracellular RNase. Proc Natl Acad Sci USA 108: 1104-1109, 2011.

23. Zhang X, Xiao Z, Chen Z, Li C, Li J, Yanhui Y, Yang F, Yang Y and Oyang Y: Comparative proteomics analysis of the proteins associated with laryngeal carcinoma-related gene 1. Laryngoscope 116: 224-230, 2006.

24. Li Y and Chen Z: Molecular cloning and characterization of $L C R G 1$ a novel gene localized to the tumor suppressor locus D17S800-D17S930. Cancer Lett 209: 75-85, 2004.

25. Guan R, Wen XY, Wu J, Duan R, Cao H, Lam S, Hou D, Wang Y, $\mathrm{Hu} \mathrm{J}$ and Chen Z: Knockdown of ZNF403 inhibits cell proliferation and induces $\mathrm{G} 2 / \mathrm{M}$ arrest by modulating cell-cycle mediators. Mol Cell Biochem 365: 211-222, 2012.

26. Tang Z: Verification of differential expression gene and its epigenic and genic study between carbo-resistance cell line and its parental cell line of ovarian carcinoma (unpublished PhD dissertation). Guangxi Medical University, 2010

27. Dweep H, Sticht C, Pandey P and Gretz N: miRWalk - database: prediction of possible miRNA binding sites by 'walking' the genes of three genomes. J Biomed Inform 44: 839-847, 2011

28. Huang da W, Sherman BT and Lempicki RA: Systematic and integrative analysis of large gene lists using DAVID bioinformatics resources. Nat Protoc 4: 44-57, 2008.

29. Huang da W, Sherman BT and Lempicki RA: Bioinformatics enrichment tools: paths toward the comprehensive functional analysis of large gene lists. Nucleic Acids Res 37: 1-13, 2009.

30. Zhang P, Gao W, Li H, Reed E and Chen F: Inducible degradation of checkpoint kinase 2 links to cisplatin-induced resistance in ovarian cancer cells. Biochem Biophys Res Commun 328 : 567-572, 2005

31. Jansen AP, Camalier CE, Stark C and Colburn NH: Characterization of programmed cell death 4 in multiple human cancers reveals a novel enhancer of drug sensitivity. Mol Cancer Ther 3: 103-110, 2004.

32. Shiota M, Izumi H, Tanimoto A, Takahashi M, Miyamoto N, Kashiwagi E, Kidani A, Hirano G, Masubuchi D, Fukunaka Y, Yasuniwa Y, Naito S, Nishizawa S, Sasaguri Y and Kohno K: Programmed cell death protein 4 down-regulates Y-box binding protein-1 expression via a direct interaction with Twist1 to suppress cancer cell growth. Cancer Res 69: 3148-3156, 2009.

33. Zhang X, Wang X, Song X, Liu C, Shi Y, Wang Y, Afonja O, $\mathrm{Ma}$ C, Chen YH and Zhang L: Programmed cell death 4 enhances chemosensitivity of ovarian cancer cells by activating death receptor pathway in vitro and in vivo. Cancer Sci 101: 2163-2170, 2010.

34. Chetram MA and Hinton CV: PTEN regulation of ERK1/2 signaling in cancer. J Recept Signal Transduct Res 32: 190-195, 2012.

35. Steelman LS, Chappell WH, Abrams SL, Kempf RC, Long J, Laidler P, Mijatovic S, Maksimovic-Ivanic D, Stivala F, Mazzarino MC, Donia M, Fagone P, Malaponte G, Nicoletti F, Libra M, Milella M, Tafuri A, Bonati A, Bäsecke J, Cocco L, Evangelisti C, Martelli AM, Montalto G, Cervello M and McCubrey JA: Roles of the Raf/MEK/ERK and $\mathrm{PI} 3 \mathrm{~K} / \mathrm{PTEN} / \mathrm{Akt} / \mathrm{mTOR}$ pathways in controlling growth and sensitivity to therapy-implications for cancer and aging. Aging 3: 192-222, 2011

36. Chalhoub N and Baker SJ: PTEN and the PI3-kinase pathway in cancer. Annu Rev Pathol 4: 127-150, 2009.

37. Okumura N, Yoshida H, Kitagishi Y, Nishimura Y and Matsuda S: Alternative splicings on p53, BRCA1 and PTEN genes involved in breast cancer. Biochem Biophys Res Commun 413: 395-399, 2011.

38. Selvendiran K, Tong L, Vishwanath S, Bratasz A, Trigg NJ, Kutala VK, Hideg K and Kuppusamy P: EF24 induces G2/M arrest and apoptosis in cisplatin-resistant human ovarian cancer cells by increasing PTEN expression. J Biol Chem 282: 28609-28618, 2007
39. Lee S, Choi EJ, Jin C and Kim DH: Activation of PI3K/Akt pathway by PTEN reduction and PIK3CA mRNA amplification contributes to cisplatin resistance in an ovarian cancer cell line. Gynecol Oncol 97: 26-34, 2005.

40. Yuan M, Tomlinson V, Lara R, Holliday D, Chelala C, Harada T, Gangeswaran R, Manson-Bishop C, Smith P, Danovi SA, Pardo O, Crook T, Mein CA, Lemoine NR, Jones LJ and Basu S: Yes-associated protein (YAP) functions as a tumor suppressor in breast. Cell Death Differ 15: 1752-1759, 2008.

41. Li J, Zou C, Bai Y, Wazer DE, Band V and Gao Q: DSS1 is required for the stability of BRCA2. Oncogene 25: 1186-1194, 2006.

42. Sakai W, Swisher EM, Jacquemont C, Chandramohan KV, Couch FJ, Langdon SP, Wurz K, Higgins J, Villegas E and Taniguchi T: Functional restoration of BRCA2 protein by secondary $B R C A 2$ mutations in $B R C A 2$-mutated ovarian carcinoma. Cancer Res 69: 6381-6386, 2009.

43. Vitari AC, Leong KG, Newton K, Yee C, O'Rourke K, Liu J, Phu L, Vij R, Ferrando R, Couto SS, Mohan S, Pandita A, Hongo JA, Arnott D, Wertz IE, Gao WQ, French DM and Dixit VM: COP1 is a tumour suppressor that causes degradation of ETS transcription factors. Nature 474: 403-406, 2011.

44. Migliorini D, Bogaerts S, Defever D, Vyas R, Denecker G, Radaelli E, Zwolinska A, Depaepe V, Hochepied T, Skarnes WC and Marine JC: Cop1 constitutively regulates c-Jun protein stability and functions as a tumor suppressor in mice. J Clin Invest 121: 1329-1343, 2011

45. Li YF, Wang DD, Zhao BW, Wang W, Huang CY, Chen YM, Zheng Y, Keshari RP, Xia JC and Zhou ZW: High level of COP1 expression is associated with poor prognosis in primary gastric cancer. Int J Biol Sci 8: 1168-1177, 2012.

46. Liang J, Song W, Tromp G, Kolattukudy PE and Fu M: Genomewide survey and expression profiling of $\mathrm{CCCH}$-zinc finger family reveals a functional module in macrophage activation. PLoS One 3: e2880, 2008.

47. Shih JY and Yang PC: The EMT regulator slug and lung carcinogenesis. Carcinogenesis 32: 1299-1304, 2011.

48. Paige AJ, Taylor KJ, Taylor C, Hillier SG, Farrington S, Scott D, Porteous DJ, Smyth JF, Gabra H and Watson JE: WWOX: a candidate tumor suppressor gene involved in multiple tumor types. Proc Natl Acad Sci USA 98: 11417-11422, 2001.

49. Chiang MF, Yeh ST, Liao HF, Chang NS and Chen YJ: Overexpression of WW domain-containing oxidoreductase WOX1 preferentially induces apoptosis in human glioblastoma cells harboring mutant p53. Biomed Pharmacother 66: 433-438, 2012.

50. Liu YY, Li L, Li DR, Zhang W and Wang Q: Suppression of WWOX gene by RNA interference reverses platinum resistance acquired in SKOV3/SB cells. Zhonghua Fu Chan Ke Za Zhi 43: 854-858, 2008 (In Chinese).

51. de Leeuw N1, Dijkhuizen T, Hehir-Kwa JY, Carter NP, Feuk L, Firth HV, Kuhn RM, Ledbetter DH, Martin CL, van Ravenswaaij-Arts CM, Scherer SW, Shams S, Van Vooren S, Sijmons R, Swertz M and Hastings R: Diagnostic interpretation of array data using public databases and internet sources. Hum Mutat 33: 930-940, 2012.

52. Moitra K, Im K, Limpert K, Borsa A, Sawitzke J, Robey R, Yuhki N, Savan R, Huang da W, Lempicki RA, Bates S and Dean M: Differential gene and microRNA expression between etoposide resistant and etoposide sensitive MCF7 breast cancer cell lines. PLoS One 7: e45268, 2012.

53. Boren T, Xiong Y, Hakam A, Wenham R, Apte S, Chan G, Kamath SG, Chen DT, Dressman H and Lancaster JM: MicroRNAs and their target messenger RNAs associated with ovarian cancer response to chemotherapy. Gynecol Oncol 113: 249-255, 2009.

54. Ko MA, Zehong G, Virtanen C, Guindi M, Waddell TK, Keshavjee $S$ and Darling GE: MicroRNA expression profiling of esophageal cancer before and after induction chemoradiotherapy. Ann Thorac Surg 94: 1094-1103, 2012

55. Eitan R, Kushnir M, Lithwick-Yanai G, David MB, Hoshen M, Glezerman M, Hod M, Sabah G, Rosenwald S and Levavi H: Tumor microRNA expression patterns associated with resistance to platinum based chemotherapy and survival in ovarian cancer patients. Gynecol Oncol 114: 253-259, 2009.

56. Jung EJ, Santarpia L, Kim J, Esteva FJ, Moretti E, Buzdar AU, Di Leo A, Le XF, Bast RC Jr, Park ST, Pusztai L and Calin GA: Plasma microRNA 210 levels correlate with sensitivity to trastuzumab and tumor presence in breast cancer patients. Cancer 118: 2603-2614, 2012 
57. Guo L, Liu Y, Bai Y, Sun Y, Xiao F and Guo Y: Gene expression profiling of drug-resistant small cell lung cancer cells by combining microRNA and cDNA expression analysis. Eur J Cancer 46: 1692-1702, 2010.

58. Wu XM, Shao XQ, Meng XX, Zhang XN, Zhu L, Liu SX, Lin J and Xiao HS: Genome-wide analysis of microRNA and mRNA expression signatures in hydroxycamptothecin-resistant gastric cancer cells. Acta Pharmacol Sin 32: 259-269, 2011.

59. Sun JY, Huang Y, Li JP, Zhang X, Wang L, Meng YL, Yan B, Bian YQ, Zhao J, Wang WZ, Yang AG and Zhang R: MicroRNA-320a suppresses human colon cancer cell proliferation by directly targeting $\beta$-catenin. Biochem Biophys Res Commun 420: 787-792, 2012

60. Zhang Y, He X, Liu Y, Ye Y, Zhang H, He P, Zhang Q, Dong L, Liu Y and Dong J: microRNA-320a inhibits tumor invasion by targeting neuropilin 1 and is associated with liver metastasis in colorectal cancer. Oncol Rep 27: 685-694, 2012.

61. Zhang H, Li W, Nan F, Ren F, Wang H, Xu Y and Zhang F: MicroRNA expression profile of colon cancer stem-like cells in HT29 adenocarcinoma cell line. Biochem Biophys Res Commun 404: 273-278, 2011.

62. Yang N, Kaur S, Volinia S, Greshock J, Lassus H, Hasegawa K, Liang S, Leminen A, Deng S, Smith L, Johnstone CN, Chen XM, Liu CG, Huang Q, Katsaros D, Calin GA, Weber BL, Bützow R, Croce CM, Coukos G and Zhang L: MicroRNA microarray identifies Let-7i as a novel biomarker and therapeutic target in human epithelial ovarian cancer. Cancer Res 68: 10307-10314, 2008.

63. Hisaoka M, Matsuyama A and Nakamoto M: Aberrant calreticulin expression is involved in the dedifferentiation of dedifferentiated liposarcoma. Am J Pathol 180: 2076-2083, 2012.

64. Li M, Balch C, Montgomery JS, Jeong M, Chung JH, Yan P, Huang TH, Kim S and Nephew KP: Integrated analysis of DNA methylation and gene expression reveals specific signaling pathways associated with platinum resistance in ovarian cancer. BMC Med Genomics 2: 34, 2009.

65. Wang Y, Niu XL, Qu Y, Wu J, Zhu YQ, Sun WJ and Li LZ: Autocrine production of interleukin- 6 confers cisplatin and paclitaxel resistance in ovarian cancer cells. Cancer Lett 295 $110-123,2010$

66. Wang Y, Qu Y, Niu XL, Sun WJ, Zhang XL and Li LZ: Autocrine production of interleukin-8 confers cisplatin and paclitaxel resistance in ovarian cancer cells. Cytokine 56: 365-375, 2011.

67. Lian L, Qu LJ, Sun HY, Chen YM, Lamont SJ, Liu CJ and Yang N: Gene expression analysis of host spleen responses to Marek's disease virus infection at late tumor transformation phase. Poult Sci 91: 2130-2138, 2012.

68. Chang MY, Yu YP, Tsai JR, Sheu CC, Chong IW and Lin SR: Combined oligonucleotide microarray-bioinformatics and constructed membrane arrays to analyze the biological pathways in the carcinogenesis of human lung adenocarcinoma. Oncol Rep 18: 569-579, 2007.

69. Morales M, Planet E, Arnal-Estape A, Pavlovic M, Tarragona M and Gomis RR: Tumor-stroma interactions a trademark for metastasis. Breast 20 (Suppl 3): S50-S55, 2011.

70. Che CL, Zhang YM, Zhang HH, Sang YL, Lu B, Dong FS, Zhang LJ and Lv FZ: DNA microarray reveals different pathways responding to paclitaxel and docetaxel in non-small cell lung cancer cell line. Int J Clin Exp Pathol 6: 1538-1548, 2013.

71. Wang JM, Wu JT, Sun DK, Zhang P and Wang L: Pathway crosstalk analysis based on protein-protein network analysis in prostate cancer. Eur Rev Med Pharmacol Sci 16: 1235-1242, 2012.

72. Wilson C, Purcell C, Seaton A, Oladipo O, Maxwell PJ, O'Sullivan JM, Wilson RH, Johnston PG and Waugh DJ: Chemotherapy-induced CXC-chemokine/CXC-chemokine receptor signaling in metastatic prostate cancer cells confers resistance to oxaliplatin through potentiation of nuclear factor- $\kappa \mathrm{B}$ transcription and evasion of apoptosis. J Pharmacol Exp Ther 327: 746-759, 2008.

73. He D, Xu Q, Yan M, Zhang P, Zhou X, Zhang Z, Duan W Zhong L, Ye D and Chen W: The NF-kappaB inhibitor, celastrol, could enhance the anti-cancer effect of gambogic acid on oral squamous cell carcinoma. BMC Cancer 9: 343, 2009.

74. Choi BH, Kim CG, Lim Y, Shin SY and Lee YH: Curcumin down-regulates the multidrug-resistance $m d r l b$ gene by inhibiting the PI3K/Akt/NFkB pathway. Cancer Lett 259: 111-118, 2008 .

75. Godwin P, Baird AM, Heavey S, Barr MP, O'Byrne KJ and Gately K: Targeting nuclear factor-kappa $B$ to overcome resistance to chemotherapy. Front Oncol 3: 120, 2013.
76. Yang G, Xiao X, Rosen DG, Cheng X, Wu X, Chang B, Liu G, Xue F, Mercado-Uribe I, Chiao P, Du X and Liu J: The biphasic role of $\mathrm{NF}-\kappa \mathrm{B}$ in progression and chemoresistance of ovarian cancer. Clin Cancer Res 17: 2181-2194, 2011.

77. Lee SC, Xu X, Lim YW, Iau P, Sukri N, Lim SE, Yap HL, Yeo WL, Tan P, Tan SH, McLeod H and Goh BC: Chemotherapyinduced tumor gene expression changes in human breast cancers. Pharmacogenet Genomics 19: 181-192, 2009.

78. Arafa el-SA,Zhu Q, Barakat BM, Wani G, Zhao Q,El-Mahdy MA and Wani AA: Tangeretin sensitizes cisplatin-resistant human ovarian cancer cells through downregulation of phosphoinositide 3-kinase/Akt signaling pathway. Cancer Res 69: 8910-8917, 2009.

79. Li QQ, Yunmbam MK, Zhong X, Yu JJ, Mimnaugh EG, Neckers L and Reed E: Lactacystin enhances cisplatin sensitivity in resistant human ovarian cancer cell lines via inhibition of DNA repair and ERCC-1 expression. Cell Mol Biol 47: OL61-OL72, 2001.

80. Menendez JA, Vellon L, Mehmi I, Teng PK, Griggs DW and Lupu R: A novel CYR61-triggered 'CYR61- $\alpha_{v} \beta_{3}$ integrin loop' regulates breast cancer cell survival and chemosensitivity through activation of ERK1/ERK2 MAPK signaling pathway. Oncogene 24: 761-779, 2005

81. Galan-Moya EM, de la Cruz-Morcillo MA, Llanos Valero M, Callejas-Valera JL, Melgar-Rojas P, Hernadez Losa J, Salcedo M, Fernández-Aramburo A, Ramon y Cajal S and Sánchez-Prieto R: Balance between MKK6 and MKK3 mediates p38 MAPK associated resistance to cisplatin in NSCLC. PLoS One 6: e28406, 2011.

82. Zhang J, Wang Y, Zhen P, Luo X, Zhang C, Zhou L, Lu Y, Yang Y, Zhang W and Wan J: Genome-wide analysis of miRNA signature differentially expressed in doxorubicin-resistant and parental human hepatocellular carcinoma cell lines. PLoS One 8: e54111, 2013

83. Lange TS, Stuckey AR, Robison K, Kim KK, Singh RK, Raker CA and Brard L: Effect of a vitamin $\mathrm{D}_{3}$ derivative (B3CD) with postulated anti-cancer activity in an ovarian cancer animal model. Invest New Drugs 28: 543-553, 2010.

84. Zhang P, Ling G, Pan X, Sun J, Zhang T, Pu X, Yin S and He Z: Novel nanostructured lipid-dextran sulfate hybrid carriers overcome tumor multidrug resistance of mitoxantrone hydrochloride. Nanomedicine 8: 185-193, 2012.

85. Calzolari A, Papucci A, Baroni G, Ficarra G, Porfirio B, Chiarelli I and Di Lollo S: Epstein-Barr virus infection and P53 expression in HIV-related oral large B cell lymphoma. Head Neck 21: 454-460, 1999.

86. Longley DB and Johnston PG: Molecular mechanisms of drug resistance. J Pathol 205: 275-292, 2005.

87. Yin F, Liu X, Li D, Wang Q, Zhang W and Li L: Bioinformatic analysis of chemokine (C-C motif) ligand 21 and SPARC-like protein 1 revealing their associations with drug resistance in ovarian cancer. Int J Oncol 42: 1305-1316, 2013.

88. Kong KA, Yoon H and Kim MH: Akt1 as a putative regulator of Hox genes. Gene 513: 287-291, 2013

89. Sharan R, Ulitsky I and Shamir R: Network-based prediction of protein function. Mol Syst Biol 3: 88, 2007.

90. Mostafavi S, Ray D, Warde-Farley D, Grouios C and Morris Q: GeneMANIA: a real-time multiple association network integration algorithm for predicting gene function. Genome Biol 9 (Suppl 1): S4, 2008.

91. Jenssen TK, Laegreid A, Komorowski J and Hovig E: A literature network of human genes for high-throughput analysis of gene expression. Nat Genet 28: 21-28, 2001.

92. Behm-Ansmant I, Rehwinkel J and Izaurralde E: MicroRNAs silence gene expression by repressing protein expression and/ or by promoting mRNA decay. Cold Spring Harb Symp Quant Biol 71: 523-530, 2006.

93. Bartel DP: MicroRNAs: genomics, biogenesis, mechanism, and function. Cell 116: 281-297, 2004.

94. Kloosterman WP and Plasterk RH: The diverse functions of microRNAs in animal development and disease. Dev Cell 11: 441-450, 2006.

95. Croce CM and Calin GA: miRNAs, cancer, and stem cell division. Cell 122: 6-7, 2005.

96. Tili E, Michaille JJ, Gandhi V, Plunkett W, Sampath D and Calin GA: miRNAs and their potential for use against cancer and other diseases. Future Oncol 3: 521-537, 2007. 